\title{
As condições das classes trabalhadoras nas circunstâncias da crise e restauração no Brasil atual
}

The conditions of the working classes in the circumstances of the crisis and restoration in current Brazil

\author{
ADILSON AQUINO SILVEIRA JÚNIOR @ \\ Universidade Federal de Pernambuco, Recife, PE, Brasil.
}

RESUMO - O presente texto objetiva analisar a situação de classe do/as trabalhadores/as forjada pela crise e a reação burguesa no Brasil. Em especial, busca avançar na caracterização da conjuntura mais recente, circunscrita pelos aspectos econômicos e a ofensiva restauradora alcançados no último biênio (2016-2017). O estudo está embasado em dados estatísticos, relatórios e levantamentos econômicos, sociais e políticos divulgados por diversas agências: organismos internacionais, organizações e movimentos políticos e meios de comunicação. Aponta para processos combinados de acirramento das condições degradantes de vida das classes trabalhadoras, como: exploração, expropriação, pauperização, repressão e despolitização. Por fim, conclui que tal quadro eleva as pressões para um inconformismo e uma inquietação social, resultando em uma tendência de agudização da luta de classes no País.

Palavras-chave: Crise econômica. Exploração. Pauperização. Expropriação. Luta de classes.

ABSTRACT - The text aims to analyze the class situation of the workers forged by the crisis and the bourgeois reaction in Brazil. In particular, the study seeks to advance the characterization of the most recent conjuncture, circumscribed by the economic aspects and the restorative offensive achieved in the last biennium (2016-2017). It is based on statistics, economic reports and political surveys published by various agencies: international organizations, political organizations, and movements and the media. It presents combined processes of intensification of the degrading conditions of working-class life: exploitation, expropriation, pauperization, repression, and depoliticization. It concludes that such a framework elevates the pressures for nonconformity and social unrest, resulting in a tendency towards an intensification of the class struggle in the country. Keywords: Economic crisis. Exploration. Pauperização. Expropriation. Class struggle. 


\section{Introdução}

$\mathrm{E}$ ste texto aborda as condições das classes trabalhadoras nas circunstâncias aviltantes da crise econômica e política do Brasil nos últimos anos. Visa destrinchar a situação de classe forjada pela crise e a reação burguesa em curso. Em especial, a análise busca avançar na caracterização da conjuntura mais recente, circunscrita pelos aspectos econômicos e a ofensiva restauradora alcançados, mormente, no último biênio. As determinações são rastreadas através de dados estatísticos, relatórios e levantamentos econômicos, sociais e políticos divulgados por diversas agências: organismos internacionais, organizações e movimentos políticos e meios de comunicação. Partimos do pressuposto de que os indicadores econômicos positivos, esboçados nos primeiros meses de 2018, corroboram para mistificar o estágio atual das contradições econômico-sociais do País. O quadro econômico e a avalanche restauradora imperantes estão implicando em um acirramento das condições degradantes de vida das classes trabalhadoras. As consequências daí derivadas, alertam para o acúmulo de contradições potencialmente disruptivas, elevando as pressões para um inconformismo e uma inquietação social, uma agudização da luta de classes. O cenário econômico-social e o movimento restauracionista condensam um assédio sob múltiplas dimensões: exploração, expropriação, pauperização, repressão e despolitização das classes trabalhadoras e subalternas no País.

\section{A ilusão da saída da crise}

Persistem as vicissitudes econômicas impostas pela crise brasileira, progressivamente deflagrada após 2011. Os sintomas que, nos primeiros meses de 2018, insinuam um desfecho positivo, nos quadros vigentes da dominação burguesa, apenas corroboram para mistificar o estágio atual das contradições econômico-sociais do País. Com efeito, a caracterização do fenômeno, ligando-o estritamente aos aspectos intrínsecos ao cenário nacional, está longe de ser satisfatória. Necessariamente, o cenário nacional restritivo da acumulação capitalista vincula-se, por múltiplas mediações, ao metabolismo da valorização do capital em nível mundial, mormente pela inserção subordinada do País na divisão internacional do trabalho e nas relações de forças políticas vigentes no imperialismo. Grosso modo, a dita crise econômica brasileira é uma expressão singular do acúmulo de contradições na produção da riqueza social, considerando três níveis de abstração: um primeiro, se refere às determinações abrangentes do que Mészáros (2002) identificou como "crise estrutural do capital", ou "crise de dominação em geral" do sistema do capital; um segundo nível, remete-nos à irrupção da crise de 2008 e às dinâmicas regressivas e destrutivas da produção que ela enseja, também em âmbito internacional; e, um terceiro nível, de maior concreção, que sintetiza em sua particularidade as determinantes anteriores, agregando a elas os seus aspectos próprios, nos conduz aos fatores que plasmam a desaceleração do crescimento econômico brasileiro, em 2011, e a sua passagem para um estado de depressão, em finais de 2014. Nos dois anos consecutivos, ocorreram, por sua vez, ponderáveis taxas de crescimento negativas $(-3,5$, em 2015, e, novamente, -3,5, em 2016) - algo apenas constatado na história econômica brasileira entre 1930 e 1931, como consequência da crise de 1929. No intervalo 2015-2016, foi a primeira vez, desde uma década, que todos os setores da economia (indústria, serviços e agropecuária) registraram, concomitantemente, taxas negativas - além dos menores níveis de investimento.

Quando assumimos o problema da crise no Brasil considerando esses três níveis de concreção, fica evidente que uma solução positiva, do ponto de vista de uma restauração capitalista, seja em que patamar for, depende das possibilidades cambiantes fornecidas no curso da crise estrutural, e das respostas satisfatórias para os fenômenos assoladores da crise de 2008. Nesses dois âmbitos, até agora não se esboçaram soluções sustentáveis ${ }^{1}$, comprimindo o raio de alternativas, e jogando uma sombra sobre a situação econômica brasileira; e essa pode, tanto estar entrando em uma fase de estabilização de taxas medíocres de crescimento, quanto apenas experimentando uma pausa de um momento crítico, para uma subsequente recidiva. De todo modo, o ano de 2017 concluiu com a primeira taxa de crescimento positiva $(1,0 \%)$ depois de dois anos negativos - e isso significa, naturalmente, a insuficiência desse crescimento 
para repor a atividade econômica, com o PIB retornando ao patamar observado do primeiro trimestre de 2011.

Dizíamos, inicialmente, que essa retomada cosmética pode turvar a visão do grau efetivo das contradições acumuladas no curso da crise, e da fragilidade dos fatores que sustentaram o indicador positivo. Quando desdobrados os dados sobre os setores econômicos que forneceram a base para esse crescimento, vemos que o agronegócio - puxado pela safra recorde, principalmente de milho e soja - foi o seu decisivo impulsionador. Isso alerta para o caráter "predatório" desse crescimento, especialmente em termos da dissipação de recursos naturais decisivos como a água (a produção agropecuária, de grãos e carne, absorve uma absurda parcela do consumo da água captada e tratada no País) ${ }^{2}$. Paralelamente, a indústria permaneceu estagnada. De outra parte, um pequeno avanço no consumo das famílias forneceu uma quota de relevo para melhoria da taxa de crescimento - algo que teria relação com um índice mais baixo da inflação, algum ganho real dos salários, liberação das contas inativas do FGTS, e aumento da massa salarial devido ao crescimento da população ocupada.

Por um lado, fica explícito que o parco crescimento auferido atrela-se aos mecanismos do que Gonçalves (2012a) classificou como "nacional-desenvolvimentismo às avessas". Em especial no que toca ao definhamento da participação da indústria de transformação no PIB (desindustrialização) e a um padrão de comércio cuja tônica é reprimarização das exportações, sinalizando para a persistência e aprofundamento da vulnerabilidade externa estrutural. Por outro lado, o incremento da população ocupada, que teria insuflado a massa salarial e o consumo das famílias, se mostrou residual e conduzido pelo aumento de ocupações em setores com grande peso da informalidade. E isso deslancha sem ameaçar, todavia, o desenfreado curso declinante do número de empregados/as, disparado no bojo da crise. Ao mesmo tempo, o consumo do Governo Federal regrediu pelo terceiro ano consecutivo (2015-2017), pressionado pela vigência da Emenda Constitucional do Teto dos Gastos Públicos, cuja imposição tem implicado em contingenciamento de relevo nas políticas sociais ${ }^{3}$, com destaque para retrocessos em áreas prioritárias no campo dos direitos humanos (direitos da juventude, criança e adolescente, igualdade racial, políticas para mulheres, segurança alimentar e nutricional, habitação, dentre outras) (INESC; OXFAM; CESR, 2017). Esse quadro tende a conformar uma paisagem aterradora, em um país com brutais assimetrias: o recrudescimento da mercantilização das necessidades de reprodução social de uma gigantesca parte das classes trabalhadoras, que acumula agora sob seus ombros um ritmo acelerado dos processos de pauperização, expropriação, exploração, despolitização e repressão. Sobre o assédio novo nos campos da expropriação e exploração, os altos níveis de desemprego e informalidade, a usurpação do fundo público (em especial das políticas sociais) para sanar a voracidade dos superlucros do capital fictício, nos dão algumas amostras, mas estão longe de saturarem o quadro dos ataques - ao qual mais à frente retornaremos. Sobre a evolução dos fatores de pauperização, despolitização e repressão-criminalização-militarização, faremos algumas indicações mais precisas nos itens subsequentes do texto.

Essas primeiras aproximações ao cenário conjuntural atual nos levam a concluir preliminarmente que o complexo de contradições econômicas, sociais e políticas que a crise desencadeou no Brasil ainda não encontrou uma solução de deslocamento. E os sinais pretensamente positivos, esboçados no início de 2018, apenas cooperam para torná-lo ainda mais mistificado. Efetivamente, o cenário conjuntural está configurando-se pelo aprofundamento das contradições: entre as classes burguesas e a massa de proletários e classes subalternas; no interior das classes possuidoras ${ }^{4}$; e na relação entre as principais classes em confronto e as frações dirigentes que buscam representá-las através do governo (aqui se registram também os conflitos no interior dessas próprias frações dirigentes). É no desdobramento dessas últimas, durante a crise, por exemplo, onde se forjam as circunstâncias decisivas para o desgaste do ciclo petista, e o desfecho do golpe institucional. A substituição da modalidade de supremacia classista vigente assentou-se em um "duplo campo de impossibilidades" que a mesma começou a portar nas circunstâncias cambiantes imposta pelas vicissitudes econômicas e as fricções políticas deflagradas na crise: no âmbito da projeção e da sustentação de um programa avançado de ofensiva sobre as condições de exploração da força de trabalho, com vistas a acirrar os patamares de extração da mais-valia e a socializar os custos do colapso econômico5; e na esfera de represamento da inquietação social acumulada ${ }^{6}$, para evitar as resistências à agenda ainda 
mais nefasta que seria necessária, e cuja imposição demandava a afirmação de mecanismos abertamente repressivos de dominação classista, em um grau até então não acionado.

Por hora, nos interessa desvelar as consequências da avalanche restauradora atual em termos no acirramento das condições degradantes de vida das classes trabalhadoras. Consequências que alertam para o acúmulo de contradições potencialmente disruptivas, porquanto elevam as pressões para um inconformismo e inquietação social nos últimos anos. A ofensiva condensa articuladamente um assédio sob múltiplas dimensões: exploração, expropriação, pauperização, repressão e despolitização das classes trabalhadoras e subalternas no país. Na sequência, nos dedicamos a esquadrinhar as expressões concretas dessa ofensiva.

\section{O acirramento da exploração}

O aumento da exploração é a "pedra de toque" da restauração atual. A crise capitalista, decorrência em última instância das contradições imanentes da forma mercadoria, impõe a necessidade de soluções para o problema de realização do valor (expresso na superprodução) e da restituição de patamares médios de extração da mais-valia (demandada pela lei tendencial da queda da taxa de lucros). A destruição de forças produtivas - como solução incontornável para a pletora de mercadorias e o incremento da exploração ocorre por diversas vias, duas das quais queremos sublinhar no caso da crise atual: o aumento da capacidade ociosa na indústria; e, ligada a ela, a expulsão da força de trabalho dos seus espaços laborais, atrelada à degradação das condições de existência do trabalho vivo. Sobre o primeiro ponto, basta observar o que ocorre após 2013: queda na produção industrial, com redução do faturamento industrial; acréscimo na ociosidade da capacidade de produção, redução na quantidade de horas trabalhadas na produção (CONFEDERAÇÃO NACIONAL DAS INDÚSTRIAS, 2015). O pouco vigor que a produção industrial começa a ganhar em 2017 não informa um cenário muito alvissareiro para o desfecho dessa trajetória destrutiva, seja pela sua base um tanto inconsistente (melhora pífia e instável do consumo e da renda do trabalho), seja pela relutância nos investimentos que a disputa eleitoral cria em 2018; isso para não mencionar os fatores de ordem externa pouco confiáveis em termos do crescimento econômico mundial.

Sobre o segundo ponto, cabe situar o papel de relevo da recomposição do exército industrial de reserva, com vistas a alavancar as taxas de mais valia. Objetivamente, houve uma escalada exponencial do desemprego. A taxa média de desemprego anual no Brasil - informa a Pnad Contínua- ficou em 12,7\% em 2017, praticamente dobrando em relação a 2014, quando chegava a 6,8\%. A média anual de 2017 indica que existem 13,2 milhões de pessoas sem emprego, um salto de $96,2 \%$ desde 2014 . Adicionemos a isso três outras reservas: uma proporção significativa de postos perdidos tinha carteira assinada; a expansão geral do desemprego combina-se com uma trajetória descendente do rendimento médio real do trabalho principal da parcela ocupada; os critérios de mensuração dos indicadores de desocupação disponíveis mistificam o grau de agravamento das inserções laborais e níveis de desemprego, já que assumem situações de subemprego como parte das ocupações - isso alerta para o fato de que a situação da força de trabalho sobrante é muito mais drástica do que os números já dramáticos sugerem7.

A melhoria na taxa de ocupação alardeada nos primeiros meses de 2018 não colabora muito para alentar esperanças. Esse dado é alcançado através de uma comparação entre trimestres (nov./dez./jan.) de 2017 e 2018, entre os quais há um acréscimo de 1,745 milhões de pessoas ocupadas. Todavia, essa massa de novas ocupações foi absorvida principalmente por setores tradicionalmente caracterizados pela dominância da informalidade, baixos salários e condições precárias e instáveis (trabalho por conta própria, trabalho familiar auxiliar, e no setor privado sem carteira de trabalho assinada) $)^{8}$. Isso representa o papel que recomposição da superpopulação relativa está assumindo na conformação de patamares mais altos de exploração e degradação do trabalho, tanto com o acréscimo da pressão que massa desocupada (e subempregada) implica, no plano da concorrência, para a sujeição a circunstâncias mais aviltantes do exército ativo, quanto na substituição de trabalhadores/as com direitos trabalhistas e melhores salários por inserções precárias mal remuneradas. 
É nesses termos de rebaixamento do valor da força de trabalho, acréscimo nos níveis de exploração e degradação das condições de existência do trabalho vivo, que se deve situar os ataques recentes - além das medidas já instaladas no final do Governo Dilma - aos direitos dos/as assalariados/as expressos:

1) Na Reforma Trabalhista (Lei no 13.467/2017), que, ao instituir o negociado sobre o legislado, aponta, na prática, para o fim da Consolidação das Leis do Trabalho (CLT) como baliza para regular as relações entre empregados e patrões. Essa reforma forja um sistema que dilata o poder do capital de decidir sobre as condições de contratação, uso e remuneração da força de trabalho. Modifica os elementos centrais da relação de emprego, ao: I) alastrar as possibilidades de uso de modalidades de contratação a termo, e introduzir a figura do contrato intermitente, do trabalhador autônomo permanente e do home office; II) facultar inúmeras formas de flexibilização da utilização do tempo de vida do/a trabalhador/a, em benefício da empresa; III) propiciar o avanço da remuneração variável e do pagamento como não salário. É evidente que tais formas de exploração do trabalho não são inéditas, mas as modificações legais indicam vetores de legalização das práticas já existentes no mercado da força de trabalho, implicando em uma maior vulnerabilidade do poder das entidades de representação dos/das trabalhadores/as. Além de criar obstáculos adicionais para os/as assalariados/as cumprirem os requisitos necessários para usufruírem dos benefícios da Seguridade Social, de um lado, e, de outro, fragilizar as fontes de financiamento desse sistema protetivo, dado o incentivo a modalidades de contratação atípicas ("pejotização", formalização do trabalho autônomo e do assalariado sem carteira assinada), aumento da instabilidade e rotatividade, e estímulo à remuneração como verba indenizatória e não salário (KREIN; GIMENES; SANTOS, 2018).

2) Na Lei da Terceirização (Lei no 13.429/2017), que permite a terceirização em todas as atividades das empresas, antes confinadas apenas às atividades-meio. Associado a isso, consubstanciase um conjunto de mecanismos que exacerba os patamares da exploração para os/as terceirizados/as: estende-se o tempo possível para a vigência do contrato temporário (antes, de 3 meses, para, agora, praticamente 9 meses) - contrato que padece de condições bem inferiores; a norma legal deixa nebuloso se suas regras aplicam-se ao setor público e ao trabalho doméstico, acarretando em insegurança jurídica e possibilidade de maior judicialização; a "pejotização", ou seja, a transformação da pessoa física (empregado) em pessoa jurídica, para evitar a aplicação da legislação trabalhista (direito a hora extra, décimo terceiro salário, seguro desemprego, direitos previdenciários, intervalo remunerado, FGTS; além do prestador arcar com os custos da uma pessoa jurídica); a "quarteirização", como possibilidade da empresa terceirizada realizar contratação da força de trabalho de outra empresa, aumentando a desproteção para o/a trabalhador/a (confusão sobre os responsáveis pela relação de trabalho e o salário não pago, calote, etc.), criando oportunidade de muitas subcontratações, que levam a fragmentação, enfraquecimento organizativo, dificuldades de fiscalização da legislação trabalhista, fiscal e previdenciária. A Lei da Terceirização sanciona, portanto, a expansão de uma forma de inserção conhecida por sua condição já precária (CUT, 2014): desproporção entre os benefícios recebidos por terceirizados/as e trabalhadores/as próprios/as da empresa (com o caráter opcional da empresa estender alguns serviços para os/as terceirizados/as); menores remunerações em relação aos/as trabalhadores/as próprios/as da empresa; jornadas de trabalho maiores, grande rotatividade, condições precárias (que agravam doenças, acidentes e mortes), preconceito, em termos da estratificação entre as categorias no ambiente de trabalho;

3) na Reforma da Previdência (cuja tramitação foi suspensa em fev. 2018, com a intervenção federal no Rio de Janeiro). A busca pela garantia da Reforma constitui uma continuidade das medidas assumidas em finais de 2014, com as MP no 664 e no 665, que aumentaram a rigidez para acesso de alguns benefícios previdenciários: alterando o cálculo do valor do auxílio doença, com tendência ao rebaixamento; restringindo o acesso à pensão por morte, ao abono salarial e ao segurodesemprego, impedindo o acúmulo do seguro-defeso com outros benefícios previdenciários 
e assistenciais. No caso da Reforma da Previdência, as mudanças significarão o alongamento do tempo de contribuição e na redução do valor das aposentadorias, falta de atratividade da previdência pública e reforço da atuação do setor privado. No essencial, a proposta atual visa a alterar: a forma de acesso a benefícios, o tipo de cálculo do benefício e o financiamento de todos os regimes previdenciários. Prejudicando os/as segurados/as, essas alterações ferem os três principais fundamentos considerados para efeitos da concessão de benefício: a idade, que é aumentada; o tempo de contribuição, que é ampliado; e o valor do benefício, que é reduzido. 0 congelamento da tramitação da Reforma não significa, entretanto, a paralisação de iniciativas do governo de alterações internas que possuem repercussão para quem acessa - como o desmonte do Serviço Social na Previdência, e a imposição de normativas como a (Memorando Circular no 6 - DIRSAT/DIRAT/DIRBEN/INSS) que proíbe a entrega do resultado da perícia ao "segurado/a" após ele/ela passar pela mesma, restringindo o direito à informação. Por outro lado, avançam alterações restritivas nas previdências dos estados e municípios, com destaque para a proliferação dos fundos para complementar a aposentadoria de servidores/as que recebem acima do teto do INSS.

Em seu conjunto, essas iniciativas colaboram para estender o tempo de trabalho sem acréscimo proporcional na forma de salário; intensificar o desgaste psicofísico dos/as trabalhadores/as, com desmantelamento dos controles que limitavam (minimamente) a jornada e as circunstâncias laborais extenuantes; a contração do tempo livre para a reposição das energias corpóreas e psíquicas do trabalho vivo; o aumento dos custos de reprodução da força de trabalho, que recai sob os ombros dos/as próprios/ as trabalhadores/as; prolongamento do tempo de trabalho excedente, através do acréscimo na extensão absoluta das jornadas, paralelo a corrosão da retribuição do tempo de trabalho necessário expressa no salário. Sob as mais variadas perspectivas, o que vemos é o "acirramento das modalidades de extração da mais-valia absoluta", que tende a assumir ponderação face ao desinvestimento, que a crise cria, na produtividade através do aprimoramento tecnológico' . E, na medida em que o capital encontra (e cria) as condições políticas e legais que permitem uma ampliação da jornada de trabalho, estabelecem-se progressivamente essas modalidades aviltantes da exploração. Ao mesmo tempo em que uma parcela de trabalhadores/as se encontra impelida para a condição existencial daquele segmento da superpopulação relativa que Marx (2013, p. 718) identificou como "estagnado": ou seja, aquela parte "[...] do exército ativo de trabalhadores, mas com ocupação totalmente irregular", cujas fileiras proporcionam ao capital um "[...] depósito inesgotável de força de trabalho disponível". "Sua condição de vida cai abaixo do nível médio normal da classe trabalhadora, e é precisamente isso que a torna uma base ampla para certos ramos de exploração do capital. Suas características são o máximo de tempo de trabalho e o mínimo de salário". Em suma: a "restauração do capital" no Brasil da crise está colocando em um grau novo a "superexploração do trabalho" 10 .

\section{O agravamento da pauperização}

O grau da superexploração se expressa também pelo "aprofundamento da pauperização da população trabalhadora e suas franjas subalternas". É palpável um agravamento dos padrões de distribuição e concentração de renda alcançados na década e meia anterior. No primeiro decênio dos anos 2000, os índices de pobreza e miséria experimentaram um decréscimo acentuado, se comparada à anterior. Entre 19922002, 3 milhões de pessoas saíram da pobreza, enquanto 4,2 milhões deixaram a miséria; esses números foram, respectivamente, 8,4 e 25,3 milhões, entre 2002-2012. Nesse último ano, a condição de pobreza e miséria englobara simultaneamente $3,6 \%$ e $8,5 \%$ da população; em 1992, tais indicadores representavam $13,7 \%$ e $31,5 \%$. O mesmo sentido de queda foi constatado na evolução do índice de Gini ou de Theil, e na razão de $20 \%$ mais ricos em relação aos $20 \%$ mais pobres (IPEA, 2015). Em torno disso, três reservas se fazem necessárias. 
Primeiro, metodologias alternativas de medição da concentração de renda no Brasil, que se pretendem mais precisas na mensuração das faixas mais ricas da população, produzem resultados adicionais para avaliar a hipótese de uma "estabilidade da desigualdade de renda entre indivíduos adultos no Brasil entre 2006 e 2012". Observando que os levantamentos domiciliares - normalmente utilizados para avaliar a distribuição de renda - tendem, dentre outras limitações, a subestimar os rendimentos mais elevados, Medeiros e Souza (2016) buscaram projetar uma análise da desigualdade a partir de dados tributários, que seriam mais precisos quanto às rendas dos estratos mais ricos. Como decorrência, aventa-se a hipótese de que a desigualdade no Brasil permanece estável entre 2006 e 2012, quando os rendimentos do topo da distribuição são estimados por informações do Imposto de Renda da Pessoa Física (IRPF). O comportamento da desigualdade verificado nas pesquisas domiciliares muda de direção quando os dados do IRPF são utilizados: ou seja, deixa de haver queda e passa a haver estabilidade.

Segundo, a contração da desigualdade de renda observada estava longe de retirar do País o título de "monumento à desigualdade social", dado por Hobsbawm (2009). Se não nos restringirmos aos limites aviltantes de mensuração utilizados pelo governo e as agências internacionais, o cenário se mostrava ainda desolador, ao final da década. O Censo 2010 detectava um nível de renda surpreendentemente ínfimo. Reconhece o próprio IBGE (2010, p. 69):

Em termos absolutos, $25 \%$ das pessoas na base da distribuição de rendimentos nacional possuíam rendimento médio nominal mensal domiciliar per capita de até $\mathrm{R} \$ 188,00$ e metade da população auferia $R \$ 375,00$, valor ainda bem inferior ao valor do salário mínimo nacional em 2010 ( $R \$ 510,00)$.

Esse último dado informa algo próximo de 100 milhões de seres humanos sobrevivendo com recursos que não bastavam para assegurar a aquisição de uma única refeição digna por dia. Contraditoriamente, o tamanho da penúria social conservada nesse transcurso (e até então não derrotada com a intrépida "luta contra a pobreza") era testemunhada no próprio raio de ação alcançado pelo Programa Bolsa Família. O Governo mesmo propagandeava, em 2013, no aniversário de dez anos desse Programa, que ele registrava 50 milhões de brasileiros/as beneficiados/as (13,8 milhões de famílias). O que significava $1 / 4$ da população brasileira declarando rendimentos de até $\mathrm{R} \$ 140$ mensais, limite máximo para inclusão no benefício, o qual alavancava a renda por família, em média, em minguados $R \$ 166,34$ (SINGER, 2015).

Terceiro, tratava-se de um fenômeno praticamente generalizado em toda a América Latina, que, além dos resultados alcançados não assumirem expressividade suficiente para tirar o Brasil do ranking dos mais desiguais (em relação ao continente, como em face das outras nações do globo), encontrava-se muito vulnerável aos ciclos econômicos internacionais (GONÇALVES, 2012b). Após 2013, no curso mesmo da crise, tal fenômeno está naufragando.

A Pnad Contínua conclui que, durante o ano de 2017, o rendimento real mensal médio experimentou uma queda de $1 \%$, em relação a 2016 . E, para a metade mais pobre da população, tal contração representou mais que o dobro, chegando a 2,5\%. O Índice de Gini, por sua vez, apenas sustentou-se em 0,549, na passagem de um ano para outro, devido a sua irrisória melhora no Sudeste (de 0,535, em 2016, para 0,529 em 2017), pois nas demais regiões do País o indicador subiu, denunciando uma maior concentração de renda ${ }^{11}$. Isso ficou explícito no fato de que, nesse ano, $1 \%$ do grupo mais rico da população auferia um rendimento médio (de todos os trabalhos) 36,1 vezes acima ( $R \$ 28.040$ ) do que recebia a metade mais pobre da população (com $R \$ 754$ ). Algo que se acentua, caso considerarmos as desigualdades regionais fundadas no desenvolvimento desigual interno do País: no Nordeste, o indicador acima chegou a 44,9 vezes, com um abrupto aumento em relação ao ano anterior (que era de 39,9 vezes). O próprio Relatório do Desenvolvimento Humano de 2016 havia anunciado que o IDH brasileiro estacionara, entre os anos em que a contração econômica adentrara em um patamar recessivo (2014-2015); o índice, que vinha crescendo desde 2010, paralisou entre esses dois últimos anos (em 0,754) (PNUD, 2016). Esses dados encontram congruência com as projeções feitas pelo próprio Banco Mundial, no relatório divulgado no início 2017, intitulado Salvaguardas contra a reversão dos ganhos sociais durante a crise econômica 
no Brasil (SKOUFIAS; NAKAMURA; MAYER, 2017). O estudo prognosticava uma elevação nos indicadores de desigualdade e pobreza no País em 2016 e 2017. O cenário mais otimista aventava o acréscimo de 2,5 milhões no número de pessoas pobres no País, enquanto no mais pessimista esse montante alcançava 3,6 milhões. Em termos da pobreza extrema, um levantamento do LCA Consultores, extraído dos microdados da Pnad Contínua, denunciou o aparecimento de 1,49 milhões de novos miseráveis entre 2016-2017; uma elevação de $11 \%$ no índice (de 6,5\% para 7,2\%), no mesmo momento em que se alardeava o fim oficial da recessão. Ao todo, isso significa que em 2017 o País acumulava 14,83 milhões de pessoas subsistindo com $\mathrm{R} \$ 136$ mensais.

A acentuação da pauperização, nessas proporções, manifesta-se, por outro lado, na possibilidade da "fome e a mortalidade infantil" voltarem a tornar-se um problema abrangente. O I Relatório Nacional Voluntário da Agenda 2030 para os Objetivos do Desenvolvimento Sustentável (ODS) (GESTOS; IDS, 2017) alerta para os efeitos regressivos da agenda restauracionista (congelamento dos gastos, reforma trabalhista e da previdência), que tendem a dificultar o acesso aos alimentos pelos mais pobres, agravando o cenário de insegurança alimentar ${ }^{12}$ e recolocando o País no Mapa da Fome da ONU. Ao mesmo tempo, a mortalidade infantil (crianças entre um mês e quatro anos de idade) salta 11\% em 2016, com expectativas de índices ainda piores para 2017, segundo dados oficiais do próprio Ministério da Saúde. Essas caracterizações, mesmo limitadas e aproximativas, destacam o "agravamento da pauperização" como uma dimensão perversa do novo patamar da superexploração da força de trabalho no bojo da crise.

\section{$4 \quad 0$ assédio das expropriações}

São as "expropriações" instiladas no bojo da ofensiva restauracionista atual que pavimentam o terreno para o "agravamento da pauperização" e o "acirramento da exploração". Uma peculiaridade se expressa no fato de que as "expropriações" vistas nos últimos anos foram franqueadas pelo golpe institucional. Mais precisamente, o próprio golpe constituiu um conduto político para expropriação, cujo desenlace abriu passagem para usurpações caucionadas por vias progressivamente mais repressivas, antidemocráticas e antinacionais. Foi uma ferramenta para a rapina dos limites legais da exploração e das proteções do trabalho, assim como tem viabilizado o avanço na pilhagem do fundo público e o assédio ao patrimônio estatal-governamental. As expropriações nutrem uma agressiva "supercapitalização", que mercantiliza absorvendo como base imediata para acumulação de capital - instâncias, políticas e serviços antes fora do circuito direto da valorização. E cujos efeitos surtiam algum impacto para o provimento público (portanto socializado, embora em proporções desiguais, pelo conjunto das classes) de determinadas condições de reprodução da força de trabalho ocupada e excedente. O resultado das expropriações é uma cumulativa pressão para a subjugação de crescentes massas humanas ao mercado da força de trabalho, dilatando o exército de reserva indispensável ao incremento da extração de mais-valia.

Além da pletora de expropriações até aqui mencionadas, é necessário destacar os efeitos potenciais e efetivos da vigência da Emenda Constitucional do Teto dos Gastos Públicos (EC n.o 95 de 2016). Dentre os seus impactos sociais destrutivos, destaca-se: a retirada do poder de controle do Poder Executivo, do Congresso e da sociedade sobre o tamanho do orçamento, agora automaticamente engessado por vinte anos; para servidores públicos, a desvalorização, com possibilidades de corte de direitos e reajustes, contenção de novas contratações (estancando abertura de novos concursos); além das projeções de forte redução da receita corrente líquida, até 2036, para a Educação (de 18\% para 11,3\%) e Saúde (de 15\% para 9,3\%); e, como consequência, fortes pressões para desvinculações, reforma na Previdência, contingenciamento de projetos, programas e serviços da Assistência Social etc. (ANFIP; DIEESE, 2017; ANFIP 2016; DIEESE, 2016). Estudos técnicos feitos pela Confederação Nacional de Municípios, em 2018, avaliam as resultantes restritivas da Lei do Teto sobre os recursos de algumas políticas sociais. Informam que as despesas do governo federal com Saúde e Educação recuaram 3,1\%, entre 2016-2017 (se descontada a inflação); em termos nominais, o gasto total nas duas áreas ficou praticamente congelado (saindo de $R \$ 191,2$ bilhões para R\$ 191,3 bilhões entre esses anos). Os recursos para a manutenção e continuidade dos serviços da 
Política de Assistência Social, por sua vez, experimentaram uma perda de mais de 16\%, entre 2016 e 2017 - afirmando uma tendência de queda que havia iniciado em 2015, e que se projeta ainda mais acentuada para as previsões de 2018 (CNM, 2018).

A Emenda Constitucional no 96 (2016) - cuja aprovação prorrogou a Desvinculação de Receitas da União (DRU) até 2023, além de estabelecer, adicionalmente, a desvinculação das receitas dos estados e municípios - colaborou, por seu turno, na perpetuação de um mecanismo sustentado há mais de duas décadas para alimentar os lucros fictícios do capital parasitário-financeiro com os recursos da Seguridade Social. Estudos com dados atualizados informam o grau do (des)financiamento do Orçamento da Seguridade Social operado pela DRU, juntamente com as renúncias tributárias sobre as contribuições sociais - outro instrumento deletério de espoliação ao qual recorrem as empresas capitalistas. Ambas atingiram o montante de $\mathrm{R} \$ 269,50$ bilhões em 2016, algo em torno de 37,60\% acima dos recursos que foram destinados, no mesmo ano, para as políticas de Saúde e Assistência Social no orçamento da União (onde juntas totalizaram R\$ 195,86 bilhões) (SALVADOR, 2017). Se acotovelando na espoliação do fundo público destinado às políticas sociais, as empresas capitalistas e os investidores institucionais operam, assim, a socialização dos custos da crise, extorquindo a massa trabalhadora de parte dos meios que subsidiam sua reprodução social. Uma tendência candente se mostra no fato de que essas extorsões estão galgando sua escalada por meios acentuadamente repressivos.

\section{$5 \quad 0$ incremento da repressão}

Ao esquadrinhar a "sombra da incontrolabilidade" condensada pela ativação dos limites absolutos do capital no estágio da crise estrutural, Mészáros (2002, p. 344) conclui estarmos sujeitos a uma tendência de determinações "crescentemente políticas" para preservação do metabolismo social. O enfrentamento do desemprego crônico coloca essas determinações de modo candente. Diz ele: "[...] a multiplicação incontrolável da 'força de trabalho supérflua' representa não apenas uma drenagem enorme de recursos do sistema, mas também uma carga potencialmente explosiva extremamente instável" (2002, p. 341-342). Como corolário, as "medidas autoritárias" se tornam imperativas pelas dificuldades crescentes de administração das condições da vida socioeconômica em deterioração. Não é ocasional que a afirmação dos governos e políticas ditos neoliberais no mundo esteja associada com o agravamento de "respostas estatais repressivas e conservadoras" à inquietação política das classes trabalhadoras e a exacerbação do "problema da violência" que a barbárie social necessariamente põe em gestação. Também não é aleatório que a crise de 2008 tenha robustecido as forças reacionárias em todas as latitudes, sobretudo após $2010^{13}$.

Na América Latina, esses efeitos políticos da crise se expressaram, inicialmente, com o desgaste e o declínio dos governos social-liberais e nacional-reformistas que haviam se erguido em meio às fissuras do bloco neoliberal dos anos 1990. Basta cotejar a atual situação - cumulativamente problemática - do chavismo na Venezuela, do masismo na Bolívia, do correismo no Equador, do kichenerismo na Argentina, da Frente Ampla no Uruguai; além das destituições, articuladas por forças reacionárias, de governos eleitos em Honduras, no Paraguai e no Brasil. Nesse último, o caráter conservador extremado dos movimentos que se adensam em meio aos conflitos das forças no ano de 2013 é evidente ${ }^{14}$. Identifica Souza (2016): iniciativas como: a União contra a Corrupção, a Greve Geral sem Sindicatos, a Marcha da Família contra o Comunismo se delinearam enquanto propostas de ação e movimentos de direita que, naquele ano, não conseguiram se impor como direção das manifestações de junho. Justo nos anos mais críticos do colapso econômico (2015-2016), as mobilizações emergentes ostentam um claro colorido reacionário. O levantamento das reivindicações desfraldadas pelas mesmas é sintomático do seu caráter: pedidos de retorno e saudações ao Golpe de 1964; agressões físicas e verbais, e perseguições, a militantes petistas ou identificados como de esquerda; discurso anticomunista, ufanista, nacionalista e elitista; ademais das manifestações de caráter religioso e hostil às pautas do movimento feminista, antirracista e LGBT. Nesse transcurso, agrupamentos e institutos declaradamente conservadores começam, igualmente, a abrolhar e angariar alguma notoriedade: 
o Movimento Brasil Livre, o grupo filofascista Revoltados On-line, o grupo Estudantes pela Liberdade; ao lado do Instituto Millenium, do Instituto Ludwig von Misese do Instituto Liberal, do Portal Conservador e do Instituto Conservador de Brasília (SOUZA, 2016).

Ademais do peso que começa a adquirir o reacionarismo conservador na esfera das forças hegemônicas, insurgem políticas governamentais abertamente repressoras. Na formação brasileira, a escalada da violência - que avulta com a barbárie social resultante da crise - desde muito é enfrentada pela sistemática "repressão e criminalização das massas pauperizadas", ao tempo em que a revolta politicamente dirigida é tratada pela "coerção e cooptação dos movimentos e organizações das classes trabalhadoras"15. Práticas tradicionais e sistemáticas de dominação classista que se desdobram atualmente na agudização do encarceramento, na evolução das políticas de segurança pública de cariz policial-punitivo (e suas ações ilegais complementares de tortura, violação, execução, formação de milícias etc.) e na complementaridade entre a "judicialização da política"16 e a espúria "militarização do Estado". ${ }^{17}$ Uma expressão das iniciativas legal-estatais com potencial criminalizador das lutas sociais - forjada na evolução da crise - foi sancionada em meio às prerrogativas de estabilidade necessária a realização dos grandes eventos esportivos: a Lei Antiterrorismo ( $\mathrm{n} 013.260$ de 16.03.2016), que instalava a possibilidade de qualificar ações políticas como "terroristas". Por hora, importa-nos destacar a mais atual tendência a "militarização do Estado" (e centralização política) que desponta nos últimos capítulos da reação burguesa à crise no país.

Logo na sua estreia, o Governo Temer se colocou para reorganizar e fortalecer o Sistema Brasileiro de Inteligência (SISBIN) e a Agência Brasileira de Inteligência (ABIN). Em maio de 2016, recriou o Gabinete de Segurança Institucional (GSI) - extinto na reforma ministerial do governo de Dilma Rousseff, ocorrida em 2015 - e devolveu ao órgão o controle da ABIN. Antes submetida a um civil, a agência passou para o comando do general Sergio Etchegoyen (novo ministro-chefe do GSI), que recebeu a missão de recuperar os poderes dos órgãos de informação. Data desse período um florescente movimento de entrega a militares de áreas do governo antes ocupadas por civis - foram os casos do Ministério da Defesa, das ações de intervenção na Segurança Pública no Rio de Janeiro, da Secretaria Nacional de Segurança Pública, da presidência da FUNAl, além de alguns cargos estratégicos de segundo escalão, como a chefia do Gabinete da Casa Civil. A partir desse ano, observa-se também que os militares deflagraram operações de Garantia da Lei e da Ordem ${ }^{18}$ em quatro estados, e a varredura em 34 presídios estaduais. Já em 2017 (outubro), a presidência aprova Lei 13.491/2017, permitindo que militares sejam julgados pela Justiça Militar por crimes praticados durante operações de rua, o que antes era imputado à justiça comum. E, ao término do ano, Temer assina o decreto que constituiu uma "Estratégia Nacional de Segurança". Decorrência da "Política Nacional de Inteligência", também sancionada por seu governo em junho de 2016, a estratégia possui como objetivo último o fortalecimento do SBI. A militarização se expressa, inclusive, no espantoso crescimento do número (e da capilaridade) de pré-candidaturas de militares da reserva para as eleições de 2018

Expressão cristalina (e laboratório) dessa tendência de militarização tem sido a intervenção federal no Rio de Janeiro para conter a situação da segurança pública no agravamento da crise econômica (Decreto n. 9.288/2018). Acionando ineditamente a aplicação do art. 34 da Constituição Federal de 1988, o Governo Federal intervém na autonomia do Estado, com as forças nacionais de segurança, e nomeia como interventor o general de exército Walter Souza Braga Neto, que assume o comando da Polícia Militar do Rio de Janeiro, da Polícia Civil e do Corpo de Bombeiros. Após dois meses da intervenção - momento em que a operação sai da fase de planejamento e entra na etapa de ação - não há sinais de uma estagnação da criminalidade e do narcotráfico. Há o acúmulo de novas contradições. O que se esboça, em termos das condições de vida das classes trabalhadoras atingidas, é a tendência à anulação dos direitos democráticos daqueles/las moradores/as dos bairros e favelas em conflito: revistas, fichamentos dos organismos de inteligência, interdição do direito de ir e vir, possibilidade de mandados de busca e apreensão coletivos. $E$ as ações planejadas apenas concentram-se em robustecer o policiamento e a militarização: ampliação e treinamento (por parte do Exército) do efetivo da Polícia Militar, aquisição de veículos e armamentos, aprimoramento das ações de inteligência, mudanças na administração financeira dos órgãos de segurança. 
Todas as frentes da reação burguesa, nos últimos capítulos da crise e restauração do capital no País, cooperam articuladamente para uma "agudização da luta de classes". Com destaque para a inquietação social das classes trabalhadoras e subalternas, atingidas pelo aprofundamento da exploração, expropriação, pauperização e repressão. Essa insatisfação social crescente anuncia-se desde alguns anos - basta cotejar as estatísticas que sinalizam a disposição para a ação grevista, o caráter massivo dos protestos de 2013, a combatividade de rua apresentada nas manifestações contra os megaeventos esportivos, a abrangência das ocupações nas escolas, institutos federais e universidades, a expressividade do movimento da Greve Geral de 28 de abril de 2017. O fenômeno próprio do último ano foi a tentativa de represamento dessa disposição, combinado com a sua canalização para os rituais e respostas da disputa eleitoral (com a tentativa de deslocamento das soluções para a vitória de candidaturas progressistas, seu intento de reanimação da crença na via da negociação parlamentar etc.) - para os quais contribuíram, no exemplo da Greve Geral de abril de 2017, as grandes centrais sindicais, mas também as forças majoritárias do PT e de algumas organizações de sua base. Assumimos a hipótese de que o conjunto dos assalariados e subalternos seguiam em um ascenso de lutas com seu cerne progressivamente direcionando-se para a resistência às ofensivas burguesas sobre as condições de vida e trabalho. No entanto, ocorreu a retração do movimento nacional contra a reação burguesa, na proporção mesma em que se canalizava a revolta para o pleito eleitoral em 2018. Se estiver correta a hipótese da agudização da inquietação proletária, o exaurido dique da via eleitoral (e da conciliação) não tardará a se romper.

\section{Considerações finais}

A persistência do cenário econômico - internacional e nacional - restritivo imposto pela crise, que condiciona a atual instabilidade política e dirigente no Estado, sinaliza para a continuidade dessa investida das classes dominantes, na qual está implicado o conjunto de assédios da avalanche restauradora esboçado acima. Uma ofensiva que prolonga o acirramento das condições degradantes de vida das classes trabalhadoras, acumulando contradições que elevam as pressões para o inconformismo e a inquietação social, uma agudização da luta de classes. Observamos que tal quadro econômico-social, e o movimento restauracionista por ele impelido, condensam um assédio sob múltiplas dimensões: exploração, expropriação, pauperização, repressão e despolitização das classes trabalhadoras e subalternas no País.

A similar taxa de crescimento econômico de 2018, em relação ao ano anterior, e o malogro das projeções de expansão da acumulação em nível mundial, sedimentam a acentuação da crise política, expressa na incapacidade das classes possuidoras encontrarem uma solução duradoura e viável, no plano das frações dirigentes que devem representar suas necessidades materiais através do Estado. Por outro lado, a insatisfação e inquietação social que os assédios às massas trabalhadoras e oprimidas tendem a acumular, não encontram, nos mais expressivos organismos da luta sindical e política dessas classes, sedimento para a mobilização balizada pela independência de classe. Diferente disso, as demonstrações da persistência nas vias conciliatórias e parlamentar-institucional de ação política têm significado uma compressão e diluição das mobilizações, em um momento de avanço de forças restauradoras nas instâncias do Estado. Com o ímpeto restaurador acentuado pelo cenário econômico, e a concentração do poder social, político e ideológico já acumulado pelas classes possuidoras, o inconformismo e a inquietação dos dominados são absorvidos por frações dirigentes como aquelas forjadas pelo governo de Jair Bolsonaro. Daí o robustecimento das medidas e pressões econômicas ultraliberais, da direitização das forças políticas, das práticas jurídico-políticas autoritárias e militarizantes, das concepções e valores obscurantistas, irracionalistas e facistizantes. 


\section{Referências}

ASSOCIAÇÃO NACIONAL DOS AUDITORES FISCAIS DA RECEITA FEDERAL DO BRASIL. Análise da Seguridade Social 2015. Brasília, DF: ANFIP, 2016.

ASSOCIAÇÃO NACIONAL DOS AUDITORES FISCAIS DA RECEITA FEDERAL DO BRASIL; DEPARTAMENTO INTERSINDICAL DE ESTATÍSTICA E ESTUDOS SOCIOECONÔMICOS. Previdência: reformar para excluir? Contribuição técnica ao debate sobre a reforma da previdência social brasileira. Brasília, DF: ANFIP; DIEESE, 2017.

ARTIGO 19 (org.). As ruas sob ataque: protestos 2014 e 2015. Setembro de 2015. Disponível em: http://artigo19.org/ blog/2015/09/10/relatorio-aponta-que-estado-brasileiro-segue-com-postura-repressiva-a-manifestacoes-de-rua/. Acesso em 9 abr. 2018.

BRASIL. Declaração Ministerial“ Um chamado urgente para uma ação decisiva sobre a água”. Brasília, mar. 2018. Disponível em: http://www.worldwaterforum8.org/pt-br/news/declara\%C3\%A7\%C3\%A3o-ministerial-busca-a\%C3\%A7\%C3\%A3odecisiva-sobre-\%C3\%A1gua. Acesso em: 20 abr. 2018.

CONFEDERAÇÃO NACIONAL DE MUNICIPIOS (CNM). Redução no orçamento da Assistência Social compromete futuro do Suas. 2. ed.: (Estudo técnico). Brasília, janeiro de 2018. Disponível em: http://www.cnm.org.br/biblioteca/exibe/3292. Acesso em 20 abr. 2018

CONFEDERAÇÃO NACIONAL DAS INDÚSTRIAS. Indicadores Industriais, ano 17, n. 8, ago. 2015.

CENTRAL ÚNICA DOS TRABALHADORES (CUT). Terceirização e desenvolvimento, uma conta que não fecha: dossiê acerca do impacto da Terceirização sobre os trabalhadores e propostas para garantir a igualdade de direitos. Secretaria Nacional de Relações de Trabalho e Departamento Intersindical de Estatística e Estudos. São Paulo: CUT, 2014.

DEPARTAMENTO INTERSINDICAL DE ESTATÍSTICA E ESTUDOS SOCIOECONÔMICOS (DIEESE). Previsão de recuperação não inspira otimismo. Boletim de Conjuntura, n. 13, fev. 2018. Disponível em: https://www.dieese.org.br/ boletimdeconjuntura/2018/boletimConjuntura013.html. Acesso em 20 abr. 2018.

DEPARTAMENTO INTERSINDICAL DE ESTATÍSTICA E ESTUDOS SOCIOECONÔMICOS (DIEESE). PEC no 241/2016: o novo regime fiscal e seus possíveis impactos. Nota Técnica $n^{\circ}$ 161, set. 2016.

FONTES, Virgínia. Capitalismo em tempos de uberização: do emprego ao trabalho. Marx e o Marxismo - Revista do NIEPMarx, [s. I.], v. 5, n. 8, p. 45-67, jul. 2017.

SOROPOSITIVIDADE, COMUNICAÇÃO E GÊNERO (GESTOS); INSTITUTO DEMOCRACIA E SUSTENTABILIDADE (IDS) (org.). Relatório Luz da agenda 2030 de desenvolvimento sustentável: síntese. [S. I.]: GESTOS; IDS, 2017. Disponível em: http:// actionaid.org.br/wp-content/files_mf/1499785232Relatorio_sintese_v2_23jun.pdf. Acesso em 20 abr. 2018.

GONÇALVES, R. Governo Lula e o nacional-desenvolvimentismo às avessas. Revista da Sociedade Brasileira de Economia Política, [s. I.], v. 31, 2012a. p. 5-30.

GONÇALVES, R. Redução da desigualdade da renda no governo Lula: análise comparativa. In: SALVADOR, Evilásio; B.EHRING, E.; BOSCHETTI, I.; GRANEMANN, S. (org.). Financeirização, Fundo Público e Política Social. São Paulo: Cortez, 2012b. p. 13-30.

HOBSBAWN, E. J. Era dos Extremos: o breve século XX. Trad. Marcos Santarrita. 9. ed. São Paulo: Companhia das Letras, 2009.

INSTITUTO BRASILEIRO DE GEOGRAFIA E ESTATÍSTICA (IBGE). Pesquisa Nacional por Amostra de Domicílios. Síntese dos Indicadores de 2009. Rio de Janeiro: IBGE; 2010.

ESTUDOS SOCIOECONÔMICOS (INESC); OXFAM BRASI; CENTRO PARA OS DIREITOS ECONÔMICOS SOCIAIS (CESR). Direitos humanos em tempos de austeridade. (Relatório). 2017. dez. Disponível em: http://static.congressoemfoco.uol.com. br/2017/12/estudo_oxfam1.pdf. Acesso em: 20 abr. 2018.

INSTITUTO DE PESQUISA ECONÔMICA APLICADA (IPEA). Nota técnica no 22: PNAD 2014: Breves análises. Brasília, dez. 2015. Disponível em: http://www.ipea.gov.br/portal/images/stories/PDFs/nota_tecnica/151230_nota_tecnica_pnad2014. pdf. Acesso em: 20 abr. 2018. 
KREIN, J.; GIMENES, D. M.; SANTOS, A. L. dos. Dimensões críticas da reforma trabalhista no Brasil. Campinas: Curt Nimuendajú, 2018

LUCE, M. S. A superexploração da força de trabalho no Brasil. Revista da Sociedade Brasileira de Economia Política, São Paulo, n. 32, p. 119-141, jun. 2012.

LUCE, M. S. Brasil: nova classe média ou novas formas de superexploração da classe trabalhadora? Trabalho, Educação e Saúde, vol. 11, n. 1, abr., p.169-190, 2013. https://doi.org/10.1590/S1981-77462013000100010

MARX, K. O capital: crítica da economia política. Livro I: o processo de produção do capital. Trad. Rubens Enderle. São Paulo: Boitempo, 2013.

MEDEIROS, M.; SOUZA, P. G. F. A estabilidade da desigualdade no Brasil entre 2006 e 2012: resultados adicionais. Rio de Janeiro, fev. 2016. (Texto para discussão, IPEA, 2170).

MÉSZÁROS, I. Para além do capital: rumo a uma teoria da transição. Trad. Paulo Cezar Castanheira e Sergio Lessa. São Paulo: Boitempo, 2002

PROGRAMA DAS NAÇÕES UNIDAS PARA O DESENVOLVIMENTO (PNUD). Human Development Report 2016: Human Development for Everyone. PNUD: New York, 2016. Disponível em: http://www.br.undp.org/content/dam/brazil/docs/ RelatoriosDesenvolvimento/undp-br-2016-human-development-report-2017.pdf. Acesso em: 20 abr. 2018.

SALVADOR, E. da S. O desmonte do financiamento da seguridade social em contexto de ajuste fiscal. Serviço Social \& Sociedade, Porto Alegre, n. 130, p. 426-446, set./dez. 2017. https://doi.org/10.1590/0101-6628.117

SINGER, A. Quatro notas sobre as classes sociais nos dez anos do lulismo. Psicologia USP, São Paulo, v. 26, n. 1, p. 7-14, abr. 2015. https://doi.org/10.1590/0103-6564D20140012

SKOUFIAS, E.; NAKAMURA, S.; MAYER, G. Salvaguardas contra a reversão dos ganhos sociais durante a crise econômica no Brasil Banco Mundial. [S. I.]: Banco Mundial, 2017. jan. Disponível em: http://documents.worldbank.org/curated/ pt/469091487328690676/Safeguarding-against-a-reversal-in-social-gains-during-the-economic-crisis-in-Brazil. Acesso em: 20 abr. 2018. https://doi.org/10.1596/26095

SOUZA, J. M. A. de. Tendências ideológicas do conservadorismo. 2016. 304 f. Tese (Doutorado em Serviço Social) Universidade Federal de Pernambuco, Recife, 2016.

\section{Notas}

1 Pense-se, por exemplo, em como é bastante recente o arrefecimento da crise de 2008, com parca retomada do crescimento mundial. Por outro lado, há indícios de um agravamento da guerra comercial, através da imposição de restrições dos EUA às importações da China, além da sua decisão de taxação do aço e do alumínio. Neste último caso, podendo afetar restritivamente o Brasil. Tal agravamento ocorre acompanhado pela exacerbação da política belicista dos países imperialistas, com destaque para o próprio EUA.

${ }^{2}$ E o atual governo brasileiro oferece muitas amostras da sua disponibilidade em mercadejar com as fontes e a distribuição de água no País - veja-se a Declaração Ministerial "Um chamado urgente para uma ação decisiva sobre a água" (BRASIL, 2018) durante o 80 Fórum Mundial da Água (março de 2018) realizado no Brasil, apelando para o envolvimento do setor privado no desenvolvimento de políticas nessa área; veja-se também a tentativa de aproximação de Temer com a Nestlé, através da reunião com o presidente da empresa (Paul Bulcke) em janeiro de 2018, em Davos, na Suíça.

${ }^{3}$ Embora tenha havido o cumprimento das metas das contas públicas, pelo quarto ano consecutivo (2014-2017) as despesas foram superiores à arrecadação com impostos e tributos, e os investimentos do governo federal caíram drasticamente. Isso se expressou no fato de que o refinanciamento da dívida pública foi o que mais cresceu, em contraste com a redução dos investimentos e dos orçamentos das áreas sociais (INESC, OXFAM; CESR, 2017).

${ }_{4}^{4}$ Algumas pistas podem sinalizar para as fricções que se avolumam entre as franjas das classes dominantes do Brasil. Talvez estejam ocorrendo impasses entre, de um lado, os segmentos da burguesia que eram beneficiados pelos investimentos do Estado, agora em um movimento de contenção, e, de outro, as frações do capital financeiro que se beneficiam dos despojos do fundo público com as políticas de austeridade. Por outra via, o chamado "tripé macroeconômico", vigente desde o segundo governo FHC, passou a desconsiderar um dos seus pontos de apoio quando o governo adotou como meta um déficit fiscal. Dos três pilares - câmbio flutuante, política de metas para a inflação e superávit primário - este último se mostrou bloqueado no curso da crise. Daí o fato de que o crescimento permanente da dívida pública, e o déficit crescente, estejam impelindo os gestores macroeconômicos do governo federal para pautar a mudança da "regra de ouro" das finanças públicas estabelecida pela Constituição Federal de 1988, relativa a proibição de que o crescimento do endividamento seja maior que as despesas de capital, cujos principais itens são os investimentos públicos e a amortização da dívida (DIEESE, 2018).

${ }^{5}$ Quanto a esse aspecto, não é que a gestão petista, e sua base, não tenham, por outro lado, se esforçado para demonstrar sua utilidade. Basta cotejarmos as medidas tomadas nos momentos finais do Governo Dilma: aprovação das MPs no 664 e no 665 de 30 dez. 2014 , convertidas 
em lei em 2015 (Leis no 13.134, de 14 jun. 2015, e № 13.135, de 17 jun. 2015, cujo objetivo foi aumentar a rigidez para acesso de alguns benefícios previdenciários; o conjunto de decretos que buscam o contingenciamento orçamentário para garantir o superávit primário (até jul. de 2015, o corte foi de R\$ 80 bilhões nas despesas sociais, através do Decreto 8.496, de 30 jul. 2015, e do Decreto 8.456, de 22 maio 2015); o aumento da previsão do gasto com o serviço da dívida pública, que alcançou R\$ 1,3 trilhões, para 2015; o aumento da taxa de juros, a Taxa SELIC (que subiu de 11,65\% para 14,25\% em set. 2015), demonstrando a disposição do governo em aumentar a remuneração do capital financeiro em meio à contenção de recursos; a publicação da MP no 680 (de 6 jul. 2015), convertida na Lei no 13.189, de 19 nov. 2015, que instituiu o "Programa de Proteção ao Emprego", permitindo às empresas com dificuldades econômico-financeiras a redução temporária da jornada de trabalho dos empregados, com a redução proporcional do salário.

${ }^{6}$ Basta cotejar os sinais de alerta que começam a ser dados antes mesmo da fase crítica da crise, e que se desdobram após o Golpe institucional: as estatísticas de greve começam a crescer a partir de 2008; ao lado crescimento dessa movimentação proletária, ocorre a explosão de protestos que marcaram o mês de junho de 2013; seguida das mobilizações populares contra os megaeventos, especialmente as ocorridas durante a Copa do Mundo da Federação Internacional de Futebol (FIFA) de 2014; o período seguinte, sendo marcado pelas manifestações pró-impeachment, em paralelo com os atos em defesa da democracia e contra o afastamento de Dilma Rousseff; já no contexto do governo Temer, nos deparamos com o movimento de ocupação das escolas, institutos federais e universidades (de outubro a dezembro de 2016); durante 2017, vemos as paralisações e mobilizações pela Greve Geral, contra a reforma da previdência e trabalhista, além daquelas pela saída do Presidente.

7 Note-se, por exemplo, os dados sobre a taxa de subutilização da força de trabalho, divulgados pelo IBGE para o primeiro trimestre de 2018. A taxa que inclui desempregados, pessoas que gostariam de trabalhar mais e aqueles que desistiram de buscar emprego, bateu o recorde de $24 \%$. Sinalizando para um quantitativo de 27,7 milhões de pessoas nessas condições - o maior número desde o início da série histórica, em 2012.

${ }^{8}$ Os principais setores empregadores, nesse caso, foram: comércio; transporte, armazenagem e correio; alojamento e alimentação; além daqueles caracterizados por atividades como serviços de informação e comunicação, serviços empresariais não financeiros, serviços profissionais, administrativos e complementares, atividade imobiliária, serviços de manutenção e reparação etc. O destaque dos representantes dos órgãos de pesquisa tem sido ocupações ligadas ao setor alimentício e dos motoristas de aplicativo - onde se mostra cristalino o problema da "uberização" (FONTES, 2017).

${ }_{9}^{9}$ A par dessa tendência, o próprio Estado empenha-se em fornecer subsídios para a intensificação da extração da mais-valia relativa. No Fórum Econômico Mundial para a América Latina (mar. 2018) ocorrido em São Paulo, o governo Temer lançou o programa "Agenda Brasileira para a Indústria 4.0", com o objetivo de oferecer financiamento público (até R\$ 5 bilhões, com prazo até 2020) para empresas que buscarem se adaptar a nova onda de modernização tecnológica da indústria (automação e robotização). Um ano antes (abr. 2017), o governo havia lançado o programa "Rota 2030", visando à elevação tecnológica das empresas com financiamento público - algo similar ao que o governo do PT propunha em 2012, com o programa "Inovar-Auto".

${ }^{10}$ Sobre o tema, consultar Luce $(2012 ; 2013)$.

${ }^{11}$ O Relatório do Desenvolvimento Humano de 2016 já havia apontado que o alto Índice de Gini brasileiro, verificado em 2015, localizava o País na classificação de 10 \% mais desigual do mundo (PNUD, 2016).

${ }^{12}$ Observe-se, por exemplo, como a proposta de orçamento para 2018 previa muitos cortes com impacto direto no agravamento da situação de fome: uma redução considerável das verbas do programa de cisternas no semiárido e dos recursos voltados para a aquisição de alimentos da agricultura familiar para distribuição em áreas mais pobres.

${ }^{13} \mathrm{~A}$ lista é longa, e um inventário aproximativo nos é fornecido por Souza (2016): na Polônia, ganha força do Partido Lei e Justiça; na Hungria, do governo de Viktor Orbén do Fidesz - União Cívica Húngara ed o movimento Hungria Melhor; na Bélgica, crescem grupos como Vlaams Belang, Voorpost (Poder Branco) e o Nova Aliança Flamenga; na Áustria, houve expressiva ascensão do candidato de extrema-direita (ou ultradireita) Norbert Hofer, do Partido da Liberdade da Áustria; na Dinamarca e na Suíça, fortalecem-se, respectivamente, o Partido Popular Dinamarquês e o Partido do Povo Suíço e Partido Liberal Radical; na Grécia, robustece o partido Aurora Dourada; na Espanha, vê-se presença marcante do Partido Popular e do Cidadãos; na Alemanha, assume ressonância a frente Alternativa para a Alemanha; na Noruega, ocorre a vitória do Partido Conservador da Noruega; na Holanda e na Suécia, projeta-se o Partido para a Liberdade, na primeira, e o Democratas da Suécia, na segunda; na Itália, o Liga do Norte aparece representando a mesma tendência; na França, há o influxo de François Holland e a projeção do Partido Conservador; no Reino Unido, ocorrem progressos da extrema direita; nos EUA, a vitória de Donald Trump; outros exemplos observam-se na Ucrânia, Bulgária, Romênia. Afirma Souza (2016, p. 271-272), por outro lado, “[...] que a rápida ascensão da extrema-direita no mundo é, também, a resposta oposta, conservadora e reacionária, à agenda ampla e relativamente difusa [...] dos movimentos contestatórios que dominaram a Turquia, o Egito, a Grécia, Alemanha, Tunísia, Madrid, Nova York, Buenos Aires, Oriente Médio, Líbia, Síria e Brasil. Greves, protestos, passeatas, manifestações, comícios, resistência e desobediência civil, marcaram esses eventos, que se sucederam internacionalmente desde a crise de 2008 e se intensificaram entre 2012 e 2013."

${ }^{14}$ Precisamos nuançar que a germinação das forças conservadoras (ligadas às igrejas, milícias, ruralistas, dentre outras) é incubada no bojo das estratégias de alianças e coalizões durante o próprio governo petista - donde o avanço de pautas como a redução da maioridade penal, do Estatuto da Família e do projeto Escola sem Partido. Vemos outro exemplo recente no encaminhamento da Reforma do Ensino Médio. O MEC aprova a Base Curricular Comum (dez. 2017) que previu a oferta do ensino religioso nas escolas, e, ao mesmo tempo, protelou a decisão sobre a incorporação da temática de gênero.

${ }^{15}$ Uma expressão da ação estatal a serviço das classes dominantes, com o intuito de sufocar manifestações populares, pode ser vista no relatório As ruas sob ataque: protestos 2014 e 2015, tratando dos casos de repressão envolvendo os protestos desses anos, onde se constatou, desde violência policial, criminalização pelos tribunais, projetos de lei restritivos, até a falta de responsabilização de agentes que cometeram violações (ARTIGO 19, 2015).

${ }^{16}$ Uma manifestação crassa do método jurídico-policial de seleção e perseguição política ocorreu no caso do julgamento e prisão de Lula, com a utilização da operação Lava Jato.

${ }^{17}$ Grosso modo, militarização aqui sugerida refere-se ao processo de adoção e uso de modelos militares, conceitos e doutrinas, procedimentos e pessoal, em atividades de natureza civil - algo entranhado na estrutura do Estado no Brasil, e que se revigora nos últimos anos. Abstraindose o caso de ditadura aberta com participação militar, no regime instalado no Golpe de 1964, pense-se em como documentos sigilosos do governo $\mathrm{FHC}$, abertos à consulta pública no Arquivo Nacional, mostraram que militantes e políticos de esquerda que participavam de seminários, encontros e fóruns contra o neoliberalismo foram monitorados pela Subsecretaria de Assuntos Estratégicos (SAE), o órgão que 
substituiu o Serviço Nacional de Inteligência (SNI), em 1990, até a criação da Agência Brasileira de Inteligência (ABIN), em 1999. Ou como, nos anos das gestões petistas no executivo federal, houve um fortalecimento da Polícia Federal e o robustecimento de suas ações, além da recorrente utilização de ação de Garantia da Lei e da Ordem também nesses governos.

${ }^{18}$ O grande número de vezes que esse tipo ação foi acionado, nos últimos anos, demonstra a escalada da militarização: entre 2010 e 2017 , a ação de Garantia da Lei e da Ordem foi empregada 29 vezes, com destaque para os casos quando da realização dos protestos na capital federal em maio de 2017, nas ações de pacificação das favelas e nos eventos esportivos da Copa do Mundo e das Olimpíadas.

Recebido em: 30/5/2018.

Aprovado em: 3/4/2019.

Publicado em: 10/10/2019.

\section{Correspondência para:}

Adilson Aquino Silveira Júnior

Universidade Federal de Pernambuco (UFPE)

Departamento de Serviço Social

Av. Prof. Moraes Rego, 1235 - Cidade Universitária

50670-901, Recife, PE, Brasil

\section{Autor:}

ADILSON AQUINO SILVEIRA JÚNIOR

Mestre e Doutor em Serviço Social pela Universidade Federal de Pernambuco (UFPE), Recife, PE, Brasil.

Professor do Curso de Serviço Social da Universidade Federal de Pernambuco (UFPE), Recife, PE, Brasil.

Orcid: https://orcid.org/0000-0001-6300-5042

E-mail: j_r1987@hotmail.com 